\title{
BMI and Static, Dynamic Balance Abilities among Undergraduate Sports Students
}

\author{
Adnan Abdulaziz Alqaraan ${ }^{1}$, Rama Mohammad Alsharksi², Nour Saad Qassem Taha ${ }^{3}$ \& \\ Aida al- Awamleh ${ }^{4}$ \\ Department of Instruction and Supervision \\ Faculty of Physical Education \\ The University of Jordan
}

\begin{abstract}
It is important to evaluate the stability of sport students. Therefore, the aim of this research was to compare the BMI, static and dynamic balance among undergraduate sports students according to academic level and gender, this study was carried out on a sample of 87 volunteers (44 males and 43 females) undergraduate sports students. The static balance was measured by flamingo balance test (FBT) and the dynamic balance was evaluated by using the stability platform with digital control model 16030. Tanita Segmental Body Composition Analyser BC-418MA used to assess BMI. The results indicated that there were no significant differences between static stability parameters between undergraduate sports students regarding to academic level whereas, a significant differences were found regarding dynamic balance. Furthermore gender differences were found regarding BMI, fat and Dynamic balance
\end{abstract}

Keywords: BMI, balance, Static, Dynamic

\section{Introduction:}

Balance is ability to maintain a stable posture with body mass center in the domain of base of support while counteracting external or internal conflicts (Abbasi , 2012). Instability of balance can demonstrate main health problems in human beings, therefore knowledge of center of gravity within the human body and support base is crucial for constant adjustments to the muscular activity and joint positioning, which simulate a motor function that ensures a connection among sight, deep sensory organs that support antigravity muscles to maintain the standing posture (Fitzpatrick, 1994). Balance depends on coordinated integration of somato-sensory, vestibular and visual input (Kisner \&Colby 2007). Furthermore, balance can be classified into static and dynamic balance. The former is the ability to stabilize the center of gravity $(\mathrm{CoG})$ within a supporting base during static standing, and the latter is the ability to maintain stable posture within a supporting base by body movement. (Hiroki et al , 2014). In fact, balance can change according to the musculoskeletal system and age (Raghubathi, 2016). The objective of this study was to compare the static and dynamic balance among undergraduate sport students regarding to gender, educational level and Body mass index (BMI). The study hypothesized that static and dynamic balance would be dissimilar among undergraduate sports students.

\section{Materials and Methods}

\section{Subjects}

A total of 87 volunteers composed of (44) males and (43) females were evaluated. The inclusion criteria were: a) academic level, b) smoking, c) age between 20 and 34 years, d) Height, e) weight, f) fat\%, g) BMI. A descriptive observational study was carried out in a cross-sectional manner without intervention,

The mean of the academic level was for 1st Year or Freshman (39) students and 4th Year or Senior students was (48) students, smoking was $40 \%$, the mean of age was $(20.83 \pm 2.87)$ years, mean height was $(1.70 \pm 0.10)$ meters, mean weight was $(65.95 \pm 14.62) \mathrm{kg}$, mean fat was $(24.71 \%)$, and mean BMI was $(22.75)\left(\mathrm{kg} / \mathrm{m}^{2}\right)$.

\section{Procedures}

All subjects were administered individually in the in the university of Jordan, all the data were systematically coded and subject to "SPSS " package. 
The study was granted approval from the University of Jordan, faculty of physical education; all participants gave their written consent to take part in the study. Participants completed the tests at the faculty laboratory though the researchers administering the tests was nearby to provide clarification if requested.

To measure the static balance, flamingo balance test (FBT) was commenced using a $(5 * 5 * 60 \mathrm{~cm})$, inadition dynamic balance ability measured using stability platform (Model 16030) that settled by Lafayette Company and BMI using Tanita Segmental Body Composition Analyser BC-418MA (Figure 1).

It was essential to compare the sig value with the value of type one error (0.05) such that if the value was $>0.05$ leading to a conclusion of no significant differences could be observed. Accordingly only one variable which is the no. of times being in the center balanced in the stability platform has a sig value $(0.001)<0.05$.

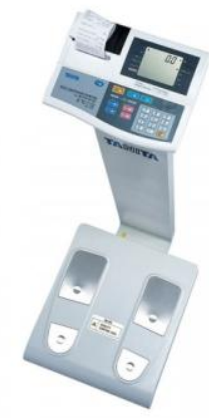

\section{Figure 1) The body composition analysis}

a) The static balance flamingo balance test (FBT) was Performed by stabilizing the center one foot above a wooden beam $(5 * 5 * 60 \mathrm{~cm}$ ) for as long as possible (Figure 2), the test starts from the start whistle and ends with Touching any part of the student's body to the ground whereas the arms should be fixed to the hips.

B) The dynamic balance test was performed by stabilizing the center using two feet for 10 seconds on a stability platform, and the students try to stabilize at the center of the platform (Figure 3).
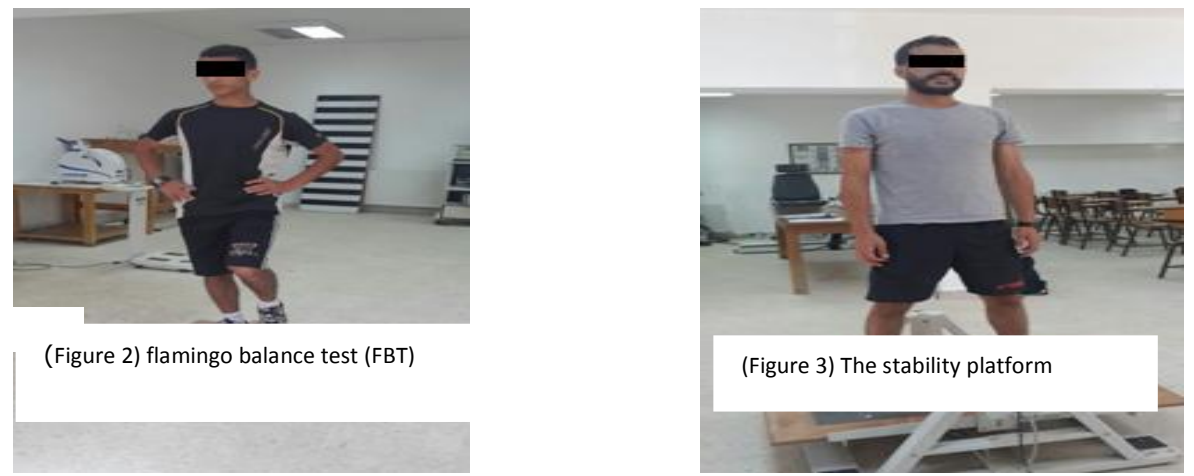

\section{Statistical analysis}

Statistical analysis was performed using Statistical Package for Social Science (SPSS), Frequencies, percentages, Means and standard deviations independent t-test was used to compare the differences. The level of significance was set at $95 \%(\mathrm{P}=0.05)$ for all observation.

\section{Results:}

The result indicated that the dynamic balance was low no time in center during 10 second, In addition, The mean value of the number of times of being balanced in the center on the stability platform was small (3.33) times with a high value of variation expressed by the standard deviation (3.45) see table (1) 
Table (1) means and standard deviations for the static and dynamic balance indicators for sport school students

\begin{tabular}{ccccccc}
$\begin{array}{c}\text { Balance } \\
\text { type }\end{array}$ & variables & $\mathbf{n}$ & Min & Max & Mean & sd \\
\hline dynamic & Time in center (s) & 82 & 0.00 & 9.00 & 0.45 & 1.18 \\
& $\begin{array}{c}\text { No. of times in } \\
\text { center (times) }\end{array}$ & 82 & 0.00 & 13.00 & 3.33 & 3.45 \\
Static & left leg (s) & 87 & 0.74 & 46.25 & 10.56 & 9.94 \\
& right leg (s) & 87 & 1.24 & 56.63 & 10.59 & 10.05
\end{tabular}

Concerning the static balance measurements, the left leg showed a mean value of (10.56) second with a high value of standard deviation reflecting the big variation among the students over the left leg balance (noting that the values range between $0.74 \mathrm{~s}$ and $46.25 \mathrm{~s}$ ) in the same context the right leg showed a balance mean time of (10.59 s) with also a greater value of variation among the students expressed by the standard deviation value (10.05)

Table (2) balance types differences among the sport school students according to academic level

\begin{tabular}{|c|c|c|c|c|c|c|c|}
\hline variables & & $\begin{array}{c}\text { Academic } \\
\text { level }\end{array}$ & $\mathbf{n}$ & mean & sd & $\begin{array}{c}\text { t } \\
\text { value }\end{array}$ & sig \\
\hline \multirow{8}{*}{$\begin{array}{l}\text { Physical } \\
\text { variables }\end{array}$} & \multirow{2}{*}{ Height } & 1st year & 39 & 1.69 & 0.10 & \multirow{2}{*}{0.54} & \multirow{2}{*}{0.591} \\
\hline & & 4 th year & 48 & 1.70 & 0.10 & & \\
\hline & \multirow{2}{*}{ Weight } & 1st year & 39 & 64.69 & 14.56 & \multirow{2}{*}{0.72} & \multirow{2}{*}{0.473} \\
\hline & & 4 th year & 48 & 66.97 & 14.73 & & \\
\hline & \multirow{2}{*}{ Fat \% } & 1st year & 39 & 24.65 & 6.43 & \multirow{2}{*}{0.058} & \multirow{2}{*}{0.95} \\
\hline & & 4 th year & 48 & 24.75 & 8.92 & & \\
\hline & \multirow{2}{*}{ BMI } & 1st year & 39 & 22.43 & 3.32 & \multirow{2}{*}{0.71} & \multirow{2}{*}{0.479} \\
\hline & & 4 th year & 48 & 23.01 & 4.10 & & \\
\hline \multirow{4}{*}{$\begin{array}{c}\text { Dynamic } \\
\text { balance }\end{array}$} & Time in & 1st year & 34 & 0.51 & 1.52 & \multirow{2}{*}{0.38} & \multirow{2}{*}{0.99} \\
\hline & center & 4 th year & 48 & 0.41 & 0.89 & & \\
\hline & \multirow{2}{*}{$\begin{array}{l}\text { No. of } \\
\text { times in } \\
\text { center }\end{array}$} & 1st year & 34 & 3.91 & 3.67 & \multirow[b]{2}{*}{1.28} & \multirow[b]{2}{*}{0.201} \\
\hline & & 4 th year & 48 & 2.92 & 3.27 & & \\
\hline \multirow{4}{*}{$\begin{array}{c}\text { Static } \\
\text { balance }\end{array}$} & \multirow{2}{*}{ left leg } & 1st year & 39 & 11.52 & 11.17 & \multirow{2}{*}{0.81} & \multirow{2}{*}{0.417} \\
\hline & & 4 th year & 48 & 9.77 & 8.86 & & \\
\hline & \multirow{2}{*}{$\begin{array}{l}\text { right } \\
\text { leg }\end{array}$} & 1st year & 39 & 11.88 & 10.35 & \multirow{2}{*}{1.07} & \multirow{2}{*}{0.285} \\
\hline & & 4 th year & 48 & 9.55 & 9.78 & & \\
\hline
\end{tabular}

The results found that there were no significant differences between subjects regarding academic level in height, weight, fat and BMI. Moreover there were no significant differences between students regarding to dynamic and static balance according to the academic level as can be seen in table 2 . Whereas there were significant differences observed regarding gender in (height, weight, fat and BMI). Table 3 shows the differences. Males were better than females in term of Dynamic balance (number of times in center). No gender differences were found regarding static balance in left or right leg. (see table 3 ) 
Table (3) balance types differences among the sport school students according to gender

\begin{tabular}{|c|c|c|c|c|c|c|c|}
\hline variables & & gender & $\mathbf{n}$ & mean & sd & t value & sig \\
\hline \multirow{8}{*}{$\begin{array}{l}\text { Physical } \\
\text { variables }\end{array}$} & \multirow{2}{*}{ Height } & males & 44 & 1.77 & 0.07 & \multirow{2}{*}{11.04} & \multirow{2}{*}{0.000} \\
\hline & & females & 43 & 1.62 & 0.06 & & \\
\hline & \multirow{2}{*}{ Weight } & males & 44 & 74.40 & 14.36 & \multirow{2}{*}{6.70} & \multirow{2}{*}{0.000} \\
\hline & & females & 43 & 57.30 & 8.66 & & \\
\hline & \multirow{2}{*}{ Fat $\%$} & males & 44 & 21.41 & 7.79 & \multirow{2}{*}{4.35} & \multirow{2}{*}{0.000} \\
\hline & & females & 43 & 28.09 & 6.43 & & \\
\hline & \multirow{2}{*}{ BMI } & males & 44 & 23.76 & 4.25 & \multirow{2}{*}{2.60} & \multirow{2}{*}{0.011} \\
\hline & & females & 43 & 21.72 & 2.89 & & \\
\hline \multirow{4}{*}{$\begin{array}{c}\text { Dynamic } \\
\text { balance }\end{array}$} & Time in & males & 41 & 0.57 & 1.47 & \multirow{2}{*}{0.94} & \multirow{2}{*}{0.349} \\
\hline & center & females & 41 & 0.33 & 0.80 & & \\
\hline & \multirow{2}{*}{$\begin{array}{l}\text { No. of } \\
\text { times in } \\
\text { center }\end{array}$} & males & 41 & 4.54 & 3.88 & \multirow[b]{2}{*}{3.35} & \multirow[b]{2}{*}{$0.001 *$} \\
\hline & & females & 41 & 2.13 & 2.48 & & \\
\hline \multirow{4}{*}{$\begin{array}{c}\text { Static } \\
\text { balance }\end{array}$} & \multirow{2}{*}{ left leg } & males & 44 & 11.60 & 10.47 & \multirow{2}{*}{0.99} & \multirow{2}{*}{0.325} \\
\hline & & females & 43 & 9.49 & 9.37 & & \\
\hline & \multirow{2}{*}{$\begin{array}{l}\text { right } \\
\text { leg }\end{array}$} & males & 44 & 12.06 & 11.99 & \multirow{2}{*}{1.38} & \multirow{2}{*}{0.169} \\
\hline & & females & 43 & 9.09 & 7.41 & & \\
\hline
\end{tabular}

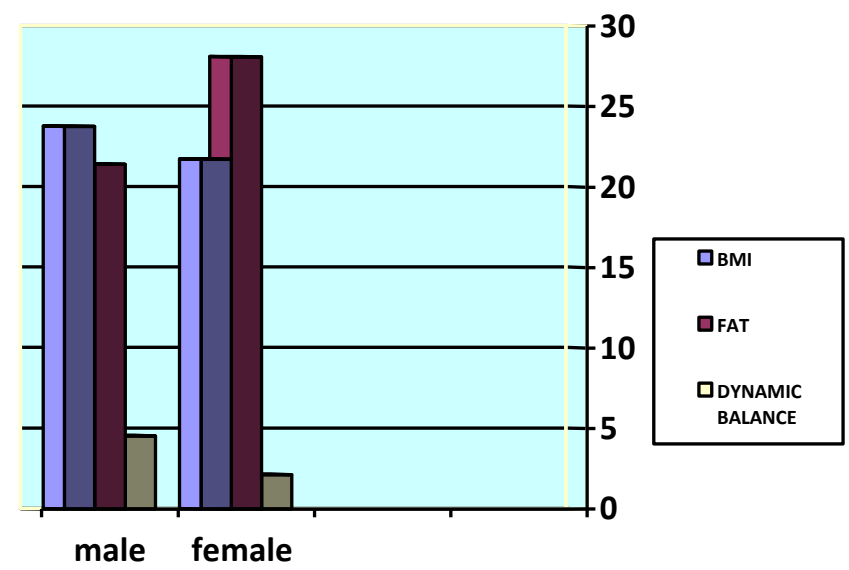

(Figure 4) BMI, Fat and dynamic gender differences

The results showed that males preformed similarity regarding to academic level. But females in 4th academic year $\mathrm{m}$ (1.42) were better than females in $1^{\text {st }}$ year in term of dynamic balance number of time in center See table 4. No significant differences were found regarding academic level. 
Table (4) balance types differences among male and female according to academic level

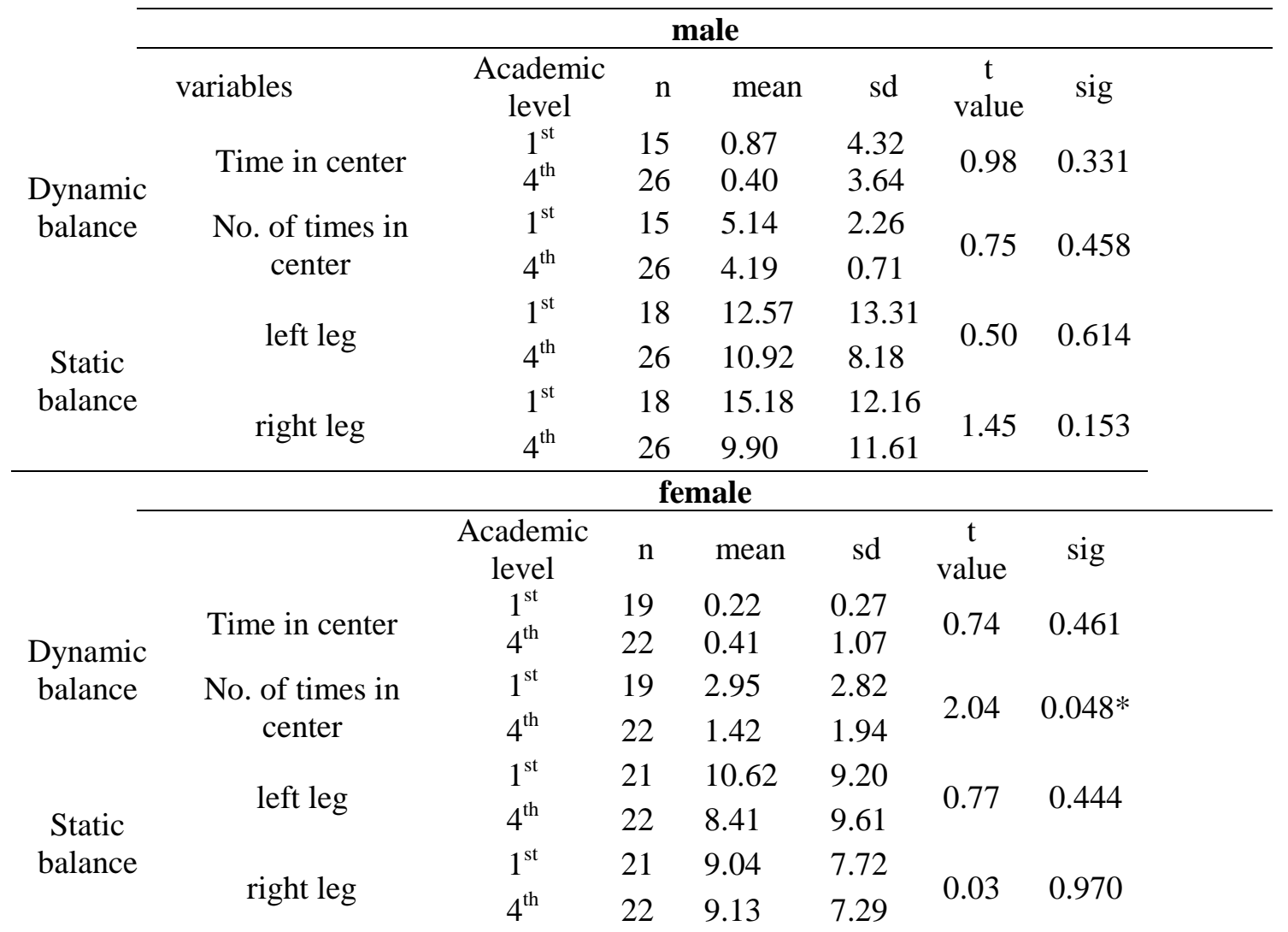

\section{Discussion}

The major purpose of this investigation was to determine if any differences of BMI, fat static and dynamic balance among undergraduate sports students according to academic level and gender.No Significant were revealed between subjects regarding academic level in height, weight, fat and BMI, dynamic and static balance. In addition, analysis revealed significant differences between subjects regarding gender were observed in height, weight, fat and BMI and Males were better than females in term of dynamic balance (number of times in center).

The most important result was that no significant differences were found between anthropometric features with dynamic balance and static. male were better than female in dynamic balance in this study male were less fat than female study Cited by Parseh and Solhjoo (2015)indicted that balance will be worsen with greater fat value. Morover athletes have better balance ability than the non-athlete (Con,2007) in this study the rseults showed that no significant differences between first and fourth acadmic level that mean the program that sport school implemented didnt impover students balance.

As a conclusion, the results didn't show any significant differences that could be observed regarding to gender and academic level among sport school student at both the static and dynamic balance tests. This shows that the academic system relies on the theoretical field rather than the practical field at the sports education school and to be more specific the curriculum didnt develop the balance capabilities of all students including freshman and graduate level. Furthermore, additional investigations are needed to confirm the

\section{References}

Abbasi R. Evaluation of static and dynamic balance and knee proprioception in young professional soccer players. Ann Biol Res 2012;3:2867-73.

Con, H.(2007). Relationship beteen balance abiity traning and sports injury risk .CLINj sports MED 37(6):547556 
Fitzpatrick, R., Rogers, D.K., and McCloskey, D.I.(1994). "Stable human standing with lower-limb muscle afferents providing the only sensory input". The Journal of Physiology, p.480,395-403.

Hiroki Sugiura, Shinichi Demura, Tamotsu Kitabayashi, Yoshimitsu Shimoyama, Daisuke Sato, Ning Xu, Yuko Asakura.(2014). "Characteristics of Static and Dynamic Balance Abilities in Competitive Swimmers". American Journal of Sports Science and Medicine. P.208-211.

Gribble, P A., \& Hertel, J. (2003)."Considerations for Normalizing Measures of the Star Excursion Balance Test”. Measurement in Physical Education and Exercise Science,7(2),89-100.

Julia Greve, Angelica Alonso, Ana Carolina P.G Bordini.(2007). "Gilberto Luis Camanho, Correlation between body mass index and postural balance Clinical science". Clinics,62(6):717-20.

Kisner C, Colby LA. Therapeutic Exercise: foundations and Techniques. 5 th ed. Philadelphia: F. A. Davis Company; 2007

Raghubathi K, P.C. krishnaswamy.(2016)." Physical growth and balance abilities of school boys".Laxmi Book publication Solpur.

Parseh A, Solhjoo MH. Studying the relationship between body mass index with speed, agility and balance in male students of 13-15 years old. Indian Journal of Fundamental and Applied Life Sciences, 2015; 5 (S2): 382-387.

Winter, D. A., Patla, A. E., \& Frank, J. S.(1990).” Assessment of balance control in humans". Medical Progress Technology, 16(1-2), 31-51. 